\title{
Ensaio sobre o conceito de transfobia
}

ISSN: 2358-0844

n. II, v. I mai. -out. 2019 p. 363-380.
Lucas Lima de Podestà ${ }^{1}$

RESUMO: O termo transfobia, através de sua tradução do termo original anglo-saxão transphobia, é um conceito em ascensão para designar e analisar as múltiplas violências contra pessoas trans - pessoas que vivem a transgeneridade. Normalmente, o termo pode ser evocado para representar um grupo heterogêneo de violências específicas que atingem mulheres transexuais, travestis, homens trans, pessoas não binárias, entre outras. Conceitualmente, a transfobia - sanção social naturalizada e normalizadora contra as pessoas trans tem uma relação com a abjeção e a estigmatização desdobradas do fenômeno da transgeneridade, no contexto de uma norma de gênero dependente da cisgeneridade. A importância do conceito pode ser analisada em relação à crescente autonomização do movimento trans no Brasil contemporâneo e a emergência do campo dos estudos transgêneros. O conceito, por sua vez, pode referir-se a outros conceitos para tratamento teórico da violência, como homofobia e genocídio.

PALAVRAS-CHAVE: transfobia; conceito; violências; trans.

Abstract: The term transfobia, from its translation of the original Anglo-Saxon term transphobia, is a rising concept for designating and analyzing the multiple forms of violence against transgender people. Normally, the term can be evoked to represent a heterogeneous group of specific violence that affects transsexual women, transvestites, trans men, non-binary persons, amongst others. Conceptually, transphobia - naturalized and normalizing social sanction against people trans - has a bond with the abjection and stigmatization deployed of the phenomenon of transgenderness, in the context of a gender norm dependent on cisgenderness. The importance of the concept can be analyzed in relation to the growing autonomization of the trans movement in Contemporary Brazil and the emergence of the field of transgender studies. The concept, likewise, may refer to other concepts for the theoretical treatment of violence, such as homophobia and genocide.

Keywords: transphobia; concept; violences; trans.

Resumen: El término transfobia, a través de su traducción del término original anglosajón transphobia, es un concepto en ascenso para designar y analizar las múltiples violencias contra personas trans - personas que viven la transgeneridad. Normalmente, el término puede ser evocado para representar un grupo heterogéneo de violencias específicas que afectan a mujeres transexuales, travestis, hombres trans, personas no binarias, entre otras. Conceptualmente, la transfobia - sanción social naturalizada y normalizadora contra las personas trans - tiene una relación con la abyección y la estigmatización desplegadas del fenómeno de la transgeneración, en el contexto de una norma de género dependiente de la cisgeneridad. La importancia del concepto puede ser analizada en relación a la creciente autonomización del movimiento trans en el Brasil contemporáneo y la emergencia del campo de los estudios transgéneros. El concepto, a su vez, puede referirse a otros conceptos para el tratamiento teórico de la violencia, como la homofobia y el genocidio.

Palabras clave: transfobia; concepto; violências; trans.

${ }^{1}$ Sociólogo. Graduado em Direito pela Universidade Federal de Goiás (UFG). Mestre em Sociologia pela UFG, linha de pesquisa "Direitos Humanos, diferença e violência". Pesquisador do Ser-Tão - Núcleo de Estudos e Pesquisas em Gênero e Sexualidade da UFG e membro do Trans-UFG, programa de extensão sobre transexualidades e travestilidades. Educante responsável pela área de Sociologia e Direitos Humanos no Cursinho Popular para ENEM Prepara Trans Goiás. E-mail: lucasdepodesta@gmail.com 


\section{Perspectivas sobre violência}

Quase a totalidade de trabalhos acadêmicos que estudam a vida de travestis e mulheres trans, e agora também dos homens trans, reconhecem o fato de que as pessoas trans são estigmatizadas em espaços sociais privados e públicos durante a vida inteira, além de sua expectativa de vida ser bem mais baixa que a média nacional. ${ }^{2} \mathrm{O}$ exercício de sua cidadania é sistematicamente obstruído, permanecendo sujeitas ao ciclo de estigmatização, pobreza e falta de educação formal e saúde, frequentemente forçadas a trabalhar em subempregos ou na prostituição. Um ciclo de violências de todas as ordens atinge as pessoas trans logo que elas decidem iniciar suas transições, experimentando os mais variados níveis de transgeneridade e resistindo à norma cisgênera.

As violências contra pessoas trans devem ser analisadas a partir dos estigmas e das relações de poder que os acompanham. Assim, é importante notar o conceito de diferença como relação social, sabendo-se de seus efeitos de hierarquização: ele "se refere à maneira como a diferença é constituída e organizada em relações sistemáticas através de discursos econômicos, culturais e políticos e práticas institucionais". (BRAH, 2006, p.362)

Tais relações sistemáticas estão inscritas no sistema de gênero, de que tratamos nos tópicos precedentes. Esse processo histórico e biopolítico compreendeu um deslocamento das noções de corpo, genitália, sexo, reprodução. (BENTO, 2006, p.109-132) Discursos científicos comparecem para naturalizar e essencializar esse modo biológico, fisiológico, anatômico de reconhecimento dos corpos, tornando-se verdade, acompanhados de outras rígidas dicotomias registrando essas noções, como a heterossexualidade compulsória acoplada ao gênero, o estatuto social, psicológico, econômico, etc. de homens e mulheres (sexismo) e a medicalização dos corpos. Portanto, a ordem de gênero produz identidades e diferenças, normalidades e anormalidades.

O estigma, definido por Goffman (1988, p.11-14), é um sinal corporal indicando um atributo com status negativo (“depreciativo"), cuja leitura deve ser feita como uma "linguagem de relações”, calcando sua filiação interacionista simbólica. O autor classifica em três tipos os estigmas: as abominações do corpo, em que estariam as características socialmente classificadas como

2 Segundo Neto Lucon (2015), jornalista cis-aliado especializado na causa trans, não existem dados sistematizados em órgãos públicos, como vemos dados do IBGE sobre expectativa de vida média de um/a brasileiro/a, hoje maior que 70 anos, sobre expectativa de vida de pessoas trans, ou travestis, ou mulheres transexuais, ou homens trans, etc. Os dados confiáveis sobre expectativa de vida de travestis, que segundo essas fontes é de 35 anos, foram produzidas pela Associação Nacional de Travestis e Transexuais (Antra).

Periódicus, Salvador, n.11, v. 1, mai-out.2019 - Revista de estudos indisciplinares em gêneros e sexualidades Publicação periódica vinculada ao Núcleo de Pesquisa NuCuS, da Universidade Federal da Bahia - UFBA ISSN: 2358-0844 - Endereço: http://www.portalseer.ufba.br/index.php/revistaperiodicus 
deformidades corporais; as culpas de caráter individual, relacionadas a algum nível de escolha ou vontade pessoal ou de intenção moral, o autor cita a homossexualidade, adicção, loucura, vícios, prisão, radicalismo político; e por último, os estigmas tribais de raça, nação, religião, relacionados a uma “transmissão através de linhagem”. "O estigma é (...) um tipo especial de relação entre atributo e estereótipo". (GOFFMAN, 1988, p.13)

Podemos aproximar o estigma das pessoas trans a dois tipos goffmanianos: as abominações do corpo e as culpas de caráter individual, considerando que o processo de transição rompe a normalidade cisgênera, inscrevendo-se diretamente no corpo, e que o processo de transformação, ainda que sutil, é lido socialmente como sendo um projeto pessoal e desejado culminando na identidade trans. As pessoas carregam ostensivamente marcadores corporais que perturbam a ordem compulsória de gênero, fundamentada em noções biologizantes e nos pares binários, pênis-vagina, homem-mulher, masculino- feminino. A estigmatização é o processo pelo qual o marcador depreciativo domina sua identidade social, conduzindo sentidos de discriminação e inferiorização através das relações sociais, restringindo suas possibilidades de vida (GOFFMAN, 1988, p.15). O gatilho que atrai o estigma sobre as pessoas trans é a transgeneridade.

Nos corpos de pessoas transgêneras convivem vagina e músculos avantajados, a exemplo de um homem transexual, ou seios e pênis, travesti ou mulher transexual que não passou pela chamada cirurgia de redesignação sexual. Suas identidades são forjadas na experiência pessoal e na subjetividade; seus corpos são anormalizados, porquanto impossíveis, incompatíveis com essa ordem de gênero. Em uma expressão, neles reside uma "intolerável ambiguidade" 3 , envolvida em processos de patologização.

Aplicando-se a ideia de abjeção de Judith Butler - explicada durante entrevista dada a Prins e Meijer, 2002 -, os corpos transgêneros são corpos abjetos, ininteligíveis (ontológica e epistemologicamente) e ilegítimos (política e normativamente); mais precisamente, são corpos “abjetificados", porque ela supõe a abjeção como um processo discursivo. (PRINS; MEIJER, 2002, p.162) São corpos que não podem ser, porém existem; isso ocorre porque o domínio da ontologia é regulamentado pelo poder: a ordem de gênero fabrica/inventa e regula corpos modelares, masculinos e femininos.

Figari (2009, p.131-133) explica que a diferença carrega a semente da abjeção, em razão dos 
processos de ontologização em termos binários. Na ordem de gênero, a hierarquização produz identidades depreciadas, subalternas, a exemplo da feminina ou da transgênera. Para o reconhecimento do eu (masculino), é necessária a negação do outro (feminino/transgênero). A abjeção é uma qualificadora emocional de estranhamento ${ }^{4}$ em relações sociais hierarquizadas, podendo ser metaforicamente analisada com as imagens da contaminação e da animalidade humana (FIGARI, 2009, p.135-137), como é o caso das identidades transgêneras.

A abjeção é o motivo do crime de ódio consumado mediante intensa violência. Dito de outra forma: "o medo ou os medos organizam o ódio". (SMIGAY, 2002, p.35) Duas características marcam o crime de ódio: a vulnerabilidade social do grupo estigmatizado e a extrema violência que acompanha o itinerário do crime (JESUS, 2014, p.113), expressa na forma como os corpos são brutalizados nesses crimes. (EFREM FILHO, 2016, p.16)

Para Xavier Crettiez (2009), violência é um ato sempre intencional de coerção que se serve de força física ou de constrangimento, para exercer ação sobre alguém ou obrigá-lo a agir de determinada maneira contra a própria vontade, gerando dor e sofrimento (CRETTIEZ, 2009, p.13-14).

O conceito de violência de gênero é um conceito específico, porém é igualmente amplo: ele se destaca de outras formas de violências tradicionalmente estudadas na sociologia, como a violência policial, e significa mais que a violência contra mulheres, porque atinge crianças e adolescentes e aqueles que se apresentam como desvio das normas do patriarcado, punidos pelos homens, a quem se autoriza a punição, conforme Saffioti (2001, p.115).

Smigay (2002, p.36-37) pondera que a própria violência de gênero constitui uma norma no sistema de gênero. Os homens são "socializados para a misoginia, para o sexismo e a homofobia, não apenas desprezam os que consideram inferiores e desvirilizados, como coletivamente acionam condutas francamente violentas” (SMIGAY, 2002, p.36). Não somente mulheres, crianças e adolescentes, mas também pessoas idosas e outros homens que recusam a masculinidade dominante sofrem os efeitos negativos dessa divergência. ${ }^{5}$

\footnotetext{
${ }^{4}$ Palavra empregada na definição de Julia Kristeva, citada em Figari (2009, p.133). Ressalte-se que há outras metáforas associadas à ideia de abjeção, que não a limitam às mencionadas no texto, como o temor à natureza, o horror, a reverência ao divino e a condição de não ser.

${ }^{5}$ Não ignoro que as feministas e outros filósofos e filósofas passaram a tratar o gênero de modo relacional, remarcando que as relações sociais de gênero caracterizam relações de poder e estão sempre em tensão, apresentando contradições
} 
Para Busin (2015, p.80-81). a violência de gênero é efeito do sistema de gênero: sendo "um ato social derivado da hierarquização naturalizada das relações de gênero e de sexo, reforçando a supervalorização de atributos socialmente considerados masculinos em detrimento das características atribuídas ao feminino". A violência de gênero nasce primeiramente em um nível simbólico, configurando "roteiros intrapsíquicos e interpessoais" que, ao hierarquizar, naturalizar e enrijecer condutas e identidades sexuais e de gênero, impedem que as diferenças "se expressem como diversidade" (BUSIN, 2015, p.256).

Assim, as pessoas transgêneras são desqualificadas e violadas por uma atribuição de gênero biologizante, com a qual não se identificam. A partir do simbólico, a violência física passa a ser também a expressão material da violência de gênero, que pretende a violação da integridade física ou a supressão da vida, acompanhada da inflição de dor e sofrimento. O conceito de violência transfóbica pode ser lido no conceito mais amplo em que se insere, a violência de gênero, acrescentando-se a especificidade das vítimas - pessoas transgêneras - e os modos frequentemente cruéis pelos quais se manifesta.

Esse tipo de violência surge com um desequilíbrio entre o sentimento de humanidade e o de abjeção; neste contexto, "a consideração da animalidade anula o caráter humano e habilita para todo ato não só de agressão e violência, mas também de extermínio. Um animal é caçado como se pode caçar uma travesti”. (FIGARI, 2009, p.135, tradução nossa) A violência transfóbica, em especial aquela que descamba em agressões físicas, parece ter um agravante em relação à violência de gênero como um conjunto, que é o sentimento de abjeção.

Na lição de Butler (2011), o "rosto", conceito de Emmanuel Levinas, é uma representação ambivalente e catacrética da nossa humanidade, precariedade da vida, e, simultaneamente, um impulso à morte, desejo de matar, e outro à vida, mandamento de preservação. (BUTLER, 2011, p.1819) O rosto pode ser mobilizado em processos discursivos para a representação ou autorrepresentação. Como efeito, pode ocorrer a humanização ou a desumanização: “[...] [A]queles que não têm oportunidade de representar a si mesmos correm grande risco de ser tratados como menos que humanos, de serem vistos como menos humanos ou, de fato, nem serem mesmo vistos" (BUTLER, 2011, p.24).

e ambiguidades várias - a mulher pode estar em cumplicidade com ou produzir a violência de gênero, bem como o homem pode recusar a violência que o sistema espera dele.

Periódicus, Salvador, n.11, v. 1, mai-out.2019 - Revista de estudos indisciplinares em gêneros e sexualidades Publicação periódica vinculada ao Núcleo de Pesquisa NuCuS, da Universidade Federal da Bahia - UFBA ISSN: 2358-0844 - Endereço: http://www.portalseer.ufba.br/index.php/revistaperiodicus 
Esse fenômeno é notável a partir do aparente paradoxo de superexposição e invisibilidade da violência contra travestis, estudada por Busin $(2015$, p.27, 51, 106, 165), principalmente a partir de suas narrativas, e essas conclusões podem ampliadas para as pessoas trans em geral. Nos discursos e nas relações sociais hierarquizadas da ordem de gênero, as travestis são representadas no masculino e frequentemente em situações degradantes ou violentas. $O$ rosto não se autorrepresenta, contudo é (mal) representado e, então, desumanizado. Não há identificação do eu com o rosto representado: "uma realização da desumanização e uma condição para a violência" (BUTLER, 2011, p.27), dada a sua identidade subalternizada, cujos corpos são ininteligíveis, ilegítimos, estigmatizados. Na escola, na mídia de massa, nos jornais, nas comunidades religiosas tradicionais de cunho cristão, nas ruas, reflete-se e multiplica-se esse processo de sub-representação e invisibilização da violência que as acompanham. O paradoxo se dissolve na realidade da constante vulnerabilidade social que marca as pessoas trans.

Para Berenice Bento (2014), ${ }^{6}$ devemos trabalhar com o conceito de transfeminicídio:" "uma política disseminada, intencional e sistemática de eliminação da população trans no Brasil, motivada pelo ódio e nojo". Para caracterizar o transfeminicídio, a autora percebeu alguns elementos: violência motivada pelo gênero e não pela orientação sexual da vítima; crimes em geral localizados nos espaços públicos, onde não ocorre a aceitação social da identidade de gênero, mas sim a deslegitimação da mesma; reconhece-se que as violências começam em espaços privados/domésticos, como a família; as mortes são ritualizadas, com o desferimento de múltiplos tiros, pedradas, facadas, etc. (espetacularização exemplar); as mortes contam com a conivência do Estado em não as apurar e não punir os assassinos; as famílias de pessoas trans não se enlutam nem reclamam seus corpos; a identidade de gênero é desrespeitada mesmo após a morte, com uma marcação linguística violenta nos diversos discursos - processos judiciais quando há, notícias, etc.

A vulnerabilidade social e as altas taxas de violência fatal contra pessoas trans, que "ainda não são vistas como seres humanos, mas como seres abjetos” (JESUS, 2014, p.105), caracterizam a situação de extrema exclusão da comunidade e da cidadania. A autora a identifica como genocídio, em razão da "expressividade numérica", do "enquadramento como crime de ódio, dada sua natureza

\footnotetext{
${ }^{6}$ Apesar de referido como artigo, o texto da autora, cujo título é "Brasil: o país do transfeminicídio", não consta da base de publicações do Centro Latino-Americano em Sexualidade e Direitos Humanos (CLAM), constando apenas de uma notícia destacada no site da organização.

7 Ela aparenta aplicar o conceito de transfeminicídio também para homens trans, ao referir-se genericamente à "população trans".
} 
de cunho discriminatório" e da "identificação com a maioria dos $\operatorname{atos}^{8}$ relacionados a genocídios". (JESUS, 2014, p.118) Por outro lado, da mesma forma que Busin (2015), ela reconhece que "não há informação oficial de como órgãos públicos brasileiros têm-se articulado para pensar e auxiliá-las [...]”. (JESUS, 2014, p.114) Enquanto não for reconhecida a identidade de gênero das pessoas trans, no Brasil, dificilmente haverá uma coleta eficiente de dados oficiais, sobre a violência que elas sofrem, em nível nacional. Tenta-se dar eco às narrativas de pessoas trans, visibilizando o que elas próprias têm a dizer, apesar da existência de dados tão esparsos e tão dependentes de ativistas do movimento social Lésbicas, Gays, Bissexuais, Travestis, Transexuais ou Transgêneros (LGBT).

O genocídio de pessoas trans pode ser entendido como a supressão e apagamento de identidades ininteligíveis e ilegítimas na ordem de gênero, sob forma de processos socialmente tolerados. O genocídio de grupos minorizados, como índios, negros, mulheres ou pessoas gênerodivergentes, banaliza a morte e as agressões que a acompanham, condição para que essa violência se sistematize e se invisibilize. É necessário, contudo, entender que os diversos tipos de violências se apresentam ou se omitem em diferentes regimes de visibilidade.

Um dos regimes de visibilidade, aquele objetivando desumanizar as pessoas trans, apenas apresentar o corpo trans brutalizado pela violência, também superexposto, de maneira espetacularizada, conforme vemos em canais de mídia de grande porte. Frequentemente culpabilizam-se as vítimas pelos eventos ocorridos. A transgressão da norma de gênero é apresentada como uma falha individual e que pode ser punida em razão de seu caráter desviante - tachado de loucura, doença, perversão, maldade, capricho, pecado, etc. - através da violência, e nesse sentido esta é visibilizada. Nesse regime, as discriminações e exclusão social que acompanham a estigmatização da vivência trans - como a expulsão do seio familiar ou do ambiente escolar, a negação do nome social, os xingamentos e ridicularização da imagem da pessoa trans em locais públicos como a rua - são também caracterizadas como violência, porém invisibilizadas - e naturalizadas - para o funcionamento da norma de gênero no nível da transfobia.

Contudo, de modo mais amplo como movimento social LGBT e modo mais local, como redes de amizades, companheirismo, familiaridade, reciprocidade, as pessoas trans se organizam, se apoiam,

\footnotetext{
${ }^{8}$ A autora utiliza a tipificação de genocídio das Nações Unidas, que corresponde, no Brasil, à da lei federal 2889, de 01.10.1956: “a) assassinatos de membros do grupo; b) atentado grave à integridade física e mental dos membros do grupo; c) c) submissão deliberada do grupo a condições de existência que acarretarão a sua destruição física, total ou parcial; d) medidas destinadas a impedir os nascimentos no seio do grupo [...]" (JESUS, 2014, p.117-118)'.
}

Periódicus, Salvador, n.11, v. 1, mai-out.2019 - Revista de estudos indisciplinares em gêneros e sexualidades Publicação periódica vinculada ao Núcleo de Pesquisa NuCuS, da Universidade Federal da Bahia - UFBA ISSN: 2358-0844 - Endereço: http://www.portalseer.ufba.br/index.php/revistaperiodicus 
tecem redes políticas mais ou menos formais, também com aliados, para resistir à violência e às diversas formas de opressão. A resistência pode se apresentar em diversos formatos, como grupos de estudos sobre conhecimento e episteme trans, grupos de acolhimento de pessoas trans vitimizadas pela violência ou expulsas de seus lares, grupos de diálogo em redes virtuais, organizações não governamentais, encontros e passeatas de rua, mobilização para a candidatura de pessoas trans nas eleições, mobilização de grupos LGBT em contenciosos judiciários, etc. Essas relações de acolhimento e respeito à vivência trans se dão sobretudo a partir da empatia e da solidariedade de pessoas trans que vivenciam a transgeneridade ou cis-aliados que compreendem a diferença e a respeitam. A empatia e a solidariedade dependem de entender que a vivência trans é uma vivência humana como qualquer outra, e que pessoas trans têm desejos, trajetórias de vida e felicidades próprias.

\section{Homofobia vs. Transfobia}

Para Daniel Borrillo (2015, p.30), “a homofobia é inconcebível sem que seja levada em consideração a ordem sexual a partir da qual são organizadas as relações sociais entre os sexos e a sexualidade". A homofobia é consequência da hierarquia existente entre sexualidades; mais exatamente, é uma interpretação da diferença entre a sexualidade prestigiada e a sexualidade estigmatizada, (BORRILLO, 2015, p.31) abrindo margem, digo, para o estabelecimento de desigualdades.

O autor reconhece a origem da homofobia no sistema heterossexista, que se fundamenta na hierarquia do masculino sobre o feminino e a atribuição da masculinidade ou feminilidade a cada pessoa a partir de critérios biológicos: “o heterossexismo é para a homofobia o que o sexismo é para a misoginia”. (BORRILLO, 2015, p.34) Para o autor, (BORRILLO, 2015, p.93) a diferença entre masculino e feminino, aparecendo frequentemente, digo, em escritos feministas como diferença sexual, é central para nossa ordem sexual, implicando a conservação da heterossexualidade e da diferença entre esta e a homossexualidade. A homofobia tem relações importantes com a masculinidade tida como "normal" de um homem. (BORRILLO, 2015, p.88-90) A construção da masculinidade envolveria a rejeição da feminilidade. A falta de virilidade corresponderia à feminilidade. A passividade corresponderia à feminilidade e a atividade, à virilidade. Sexismo e homofobia são, portanto, interligadas de acordo com Borrillo.

A homofobia surge como um conjunto de emoções, práticas, instituições e ideologia, (BORRILLO, 2015, p.35) esta última tanto sistemática quanto normativa, que promove e prestigia a heterossexualidade e a monogamia e que engendra mecanismos de diferenciação, cura, 
segregação e extermínio dos homossexuais. (BORRILLO, 2015, p.64) O autor identifica um mecanismo de subjetivação, dentro desse aparato ideológico, que convence discursivamente os homossexuais e alvos da homofobia a integrarem o sistema pela assunção de que a diferença seria essencial ou natural, ou seja, um estigma ou um marcador como uma sua identidade, provocando sua conformação ao heterossexismo.

A homossexualidade já foi nomeada como selvageria, imoralidade, doença, loucura, perversão, degenerescência. (BORRILLO, 2015, p.36) A ideia da homossexualidade como uma prática errada e, portanto, passível de algum tipo de controle ganhou sua maior força e institucionalidade na passagem da noção de que ela seria um vício da natureza enquanto ordem moral para a noção em que ela seria uma sexualidade anormal e desviada, sob uma perspectiva científica. A busca das causas da homossexualidade, nesse contexto, torna-se uma expressão explícita de homofobia porque é pressuposta uma sexualidade íntegra, normal, correta. (BORRILLO, 2015, p.63,71)

No percurso do conceito de homofobia, sua formulação inicial dava conta do fenômeno na instância individual e psicológica, originando o sentido mais popular do conceito: o medo, ódio, aversão aos homossexuais. (BORRILLO, 2015, p.21) As abordagens da psicologia localizam a homofobia na personalidade e explicam o comportamento homofóbico como "mecanismo de defesa", “distúrbio de personalidade”, "relação problemática com a própria sexualidade”. (BORRILLO, 2015, p.99) $\mathrm{O}$ autor assume que a origem da homofobia é estrutural em relação à ordem sexual para dizer que essa interpretação é muito restritiva por aproximar a homofobia de um terror ou ódio irracionais, patológicos e, desse modo, obstruir a análise da violência homofóbica e de seu funcionamento institucional e ideológico. (BORRILLO 2015, p.96)

Em minha opinião, o conceito de homofobia assim como estudado por Daniel Borrillo é produtivo no sentido de que ele se afasta cada vez mais da leitura individualizante - que isola o homofóbico de uma relação social, ou da sociedade/cultura homofóbica - e parte para leituras mais sociológicas, antropológicas e históricas. O autor tem a virtude de ligá-lo diretamente com o sistema de gênero, nomeado por ele como "ordem sexual". A interpretação ampliada da homofobia relata o funcionamento do sistema de gênero.

O conceito de homofobia às vezes é tomado como o conceito guarda-chuva para as violências contra pessoas LGBT em geral, inclusive com a justificativa de fluência de texto ou "economia de linguagem”. (BORRILLO, 2015, p.23) Para mim, ele serve para o marcador de orientação homossexual, mas não para outras orientações sexuais ou para identidade/expressão de gênero. Nesse 
contexto, como guarda-chuva, poderia ser usado para a referência à violência contra lésbicas, bissexuais, travestis, transexuais, pessoas trans, assexuais e intersexuais e queer, um grupo de pessoas altamente heterogêneo. Nesse movimento, ficam mais distantes os conceitos específicos, como a transfobia, lesbofobia ou bifobia.

Como muitos outros, Borrillo igualmente identifica no sistema de gênero ou "ordem sexual" a origem da homofobia, sem mencionar a importância do marcador da diferença, a prática ou identidade divergente da norma, localizado no corpo transviado, e o que significa a transgressão da norma, no caso da homofobia, a prática homossexual como transgressão da heterossexualidade obrigatória.

Desde que iniciei leituras sistemáticas sobre o movimento social de LGBT, os modos de existência de LGBT e violência contra LGBT - sendo que esses dois primeiros temas aparecem como necessários porém subsidiários ao terceiro, central nesse ensaio -, venho notando que o tratamento teórico na análise da violência contra LGBT nos traz uma questão cada vez mais sensível: a preponderância do uso do conceito de homofobia para referência a violências muito diversas que acometem pessoas LGBT. O conceito de transfobia tem sido mais largamente utilizado dentro do movimento social e somente graças a uma reorganização do movimento social LGBT através das redes comunicacionais eletrônicas e digitais - como a internet - a partir da década de 2010, em que o uso de "transgênero/a" e "transfobia" se torna cada vez mais disseminado. O uso de homofobia como termo guarda-chuva é bastante usual, entrando assim em contradição com o novo termo para nomear a violência específica contra pessoas trans: transfobia.

Em sua dissertação, Carvalho (2011) discute a contraposição entre os conceitos de homofobia e transfobia, articulando vozes do campo realizado e de ativistas do movimento social. Uma das principais bandeiras de luta do movimento social LGBT envolve o reconhecimento legal da diversidade sexual e de gênero, integrando os sujeitos políticos como cidadãos. Frequentemente associam-se a discriminação e o preconceito contra LGBT a algum tipo de violência e esta à criminalidade - consequentemente, tornou-se uma espécie de senso comum entre ativistas advogar pela criminalização de atos violentos contra LGBT, reduzidos à figura da homofobia. Carvalho (2011, p.126-127) menciona o apoio de entrevistadas ao projeto de lei da câmara dos deputados (PLC) número 122 de $2006,{ }^{9}$ que pretende a criminalização da homofobia.

\footnotetext{
${ }^{9}$ A tramitação do projeto associado, o PLC n. 5003, sobre atos de discriminação em razão da orientação sexual é de 2001 , ainda mais antigo.
} 
É notório que esse projeto de lei tenha surgido antes de um projeto como o PLC número 5002 de 2013, que trata do direito à identidade de gênero: primeiro, porque a homofobia tem prevalência no movimento social e no senso comum, como conceito de violência; segundo, porque a violência está associada aos crimes que atacam e destroem o corpo de pessoas LGBT, e não outras violências mais sutis, de ordem discursiva ou que obstruem diretamente a realização de direitos. O projeto de criminalização da homofobia, portanto, tem maior prevalência, visibilidade e antiguidade dentro do próprio movimento social. O surgimento de uma nova pauta LGBT, como o projeto de lei de identidade de gênero, pode estar produzindo tensões comparáveis àquelas que são sensíveis quando visualizamos as contradições entre os conceitos de homofobia e transfobia.

Essas contradições são faces daquela entre homofobia e transfobia como conceitos. Para uma interpretação, a homofobia é guarda-chuva para as violências contra pessoas LGBT, incluída a transfobia; em outra, a homofobia e a transfobia não se relacionam por serem conceitos um específico em relação ao outro. (CARVALHO, 2011, p.128-129) Algumas ativistas e pessoas trans dizem que a lei contra a homofobia poderá punir atos de violência contra travestis, que seriam homossexuais; outras dizem que há pessoas que discriminam travestis e transexuais, mas não discriminam homossexuais; outras ativistas ressaltavam a "visibilidade do estigma como principal divisor de águas entre a 'homofobia' e a 'transfobia" e que os crimes transfóbicos são muito mais "cruéis" e "hediondos". (CARVALHO, 2011, p.129)

O surgimento, adoção e frequência do uso do conceito de "transfobia", primeiramente dentro do movimento social e/ou entre pessoas trans ativistas acadêmicas - respaldado também nas elaborações teóricas do conceito de "transgeneridade" - tem um contexto histórico longo e mais amplo, que remete à história do próprio movimento LGBT. No Brasil, a fragmentação do movimento homossexual, a partir da redemocratização, deu lugar a uma posterior especificação em movimentos mais autônomos (primeiramente o movimento de travestis. A consolidação do movimento trans envolveu alguma intervenção a partir de ordens discursivas, a exemplo das mídias sociais eletrônicas e virtuais - ou a academia, com a finalidade de alterar os regimes de visibilidades para o combate dos estigmas e processos violentos afetando as pessoas trans. É nesse contexto que faz sentido a concepção e uso de conceitos específicos representando a realidade de vida das pessoas trans, como os processos de transição, alteração e autopercepção do corpo trans, associados/relativos ao conceito de "transgeneridade" e as violências específicas contra elas, como a imposição do gênero ou o desrespeito do nome, "transfobia".

Periódicus, Salvador, n.11, v. 1, mai-out.2019 - Revista de estudos indisciplinares em gêneros e sexualidades Publicação periódica vinculada ao Núcleo de Pesquisa NuCuS, da Universidade Federal da Bahia - UFBA ISSN: 2358-0844 - Endereço: http://www.portalseer.ufba.br/index.php/revistaperiodicus 
A teoria não se divorcia da prática e nessa contradição entre conceitos podemos ver a tensão dentro do próprio movimento LGBT. Há setores do próprio movimento que não aceitam a adoção de conceitos específicos como a transfobia pela razão de que teria um "grande potencial desaglutinador". (CARVALHO, 2011, p.130)

\section{Transfobia}

Em uma antologia Transgender studies reader em dois volumes (de 2007 e 2013), atestando a vivacidade e explosividade dos estudos transgêneros em países de língua inglesa, eu pude notar - e relato logo abaixo - que o conceito de transfobia (transphobia), ao contrário de transgênero, "transgender", com incontáveis remissões por inúmeros capítulos, porquanto fundamental, ou cisgênero, "cisgender", que é o objeto de um capítulo inteiro do segundo volume, ganhou vários comentários esparsos, porém não tão diretos e extensos quantos os dois primeiros conceitos. Entretanto, o uso reiterado de transfobia me fez entender que seu conteúdo é relativamente consensual.

Segundo Kate Bornstein (2006, p.238), transfobia é uma palavra em voga entre transexuais, significando, entre muitas coisas, o medo de cruzar [a barreira de gênero], o medo de transgredir ou o medo ou ódio contra quaisquer pessoas moradoras das fronteiras do gênero. Transfobia pode significar uma causa definida de violência ou uma motivação para violência. (LAMBLE, 2013, p.3132) Não somente para sugerir o medo às pessoas trans, transfobia também se refere aos comportamentos negativos - ódio, repulsa, raiva ou indignação - contra pessoas trans em razão de sua transgeneridade; tais comportamentos vão abrangendo desde insultos verbais a agressões físicas e assassinatos. (BETTCHER, 2013, p.280) A autora, no contexto de seu trabalho, afirma que exposição genital como forma de verificação de gênero é uma forma de violência transfóbica (BETTCHER, 2013, p.281).

Citando Jay Prosser na abertura de seu capítulo, Cressida Heyes aduz que transfobia pode significar literalmente o medo ao indivíduo em transição, a estigmatização de transexuais como não sendo homens ou mulheres reais. (HEYES, 2013, p.201) Sob essa ideia, ela adiante tece comentários contundentes às elaborações teóricas de determinadas feministas que se autodenominam como radicais que não somente são hostis às pessoas trans, à transgeneridade, mas fazem da desidentificação, objetificação, negação da agência e patologização um ponto de vista “crítico". (HEYES, 2013, p.203-211)

Considero o conceito de transfobia adequado para a análise da violência contra pessoas trans.

Periódicus, Salvador, n.11, v. 1, mai-out.2019 - Revista de estudos indisciplinares em gêneros e sexualidades Publicação periódica vinculada ao Núcleo de Pesquisa NuCuS, da Universidade Federal da Bahia - UFBA ISSN: 2358-0844 - Endereço: http://www.portalseer.ufba.br/index.php/revistaperiodicus 
Reconheço, por um lado, que o conceito de transfobia não é indispensável para o tratamento teórico, tampouco é uma categoria analítica ou de conhecimento imprescindível para analisar as violências específicas contra pessoas trans. Por outro lado, reconheço também que o conceito tem uma densidade interessante para esses objetivos, considerando-se que normalmente ele se refere a um conjunto heterogêneo de violências contra pessoas trans, como a violência moral, sexual, física, discursiva, simbólica, etc. O conceito de transfobia também se refere a violências muito específicas que atinge pessoas trans, como a exposição genital para verificação do gênero, uma violência correlata à generalização - imposição forçada do gênero - e o desrespeito ao nome social, escolhido pela pessoa trans. Assim como homofobia, o conceito de transfobia remete a processos violentos em níveis massificados ou coletivos, não apenas reportando-se a comportamentos individuais ou à literalidade do sufixo "fobia", e também remete a modos específicos de fazer e pensar ciência, a exemplo do feminismo que se autodenomina radical transfóbico, epítome da transfobia epistêmica.

A transfobia é uma sanção normalizadora à transição de gênero e à violação das normas de gênero que se inscrevem no corpo. A violência transfóbica atua em um nível discursivo, por discriminações sutis, de modo que a rejeição à transgeneridade circula nos discursos, entre as pessoas antes mesmo que elas iniciem suas transições e entendam-se pessoas trans. Igualmente, a transfobia participa do grupo de violências de gênero, com sua especificidade característica, alcançando gravíssimas agressões físicas e assassinatos. Socialmente generalizada e acompanhada de crimes de ódio, a transfobia é um componente do genocídio trans no Brasil.

Tanto a homofobia quanto a transfobia têm uma raiz comum - o sistema de gênero - e cada uma delas toma certas especificidades. Nele, qualquer rompimento da continuidade e da coerência do sexo, corpo, eu e desejo sujeita a pessoa transgressora a variadas formas de violência. A divergência da norma da heterossexualidade sujeita a pessoa à homofobia, bem como a divergência da norma de gênero sujeita a pessoa à transfobia. Frequentemente a homofobia e a transfobia são definidas como associadas ao medo e ao ódio ao diferente. (SMIGAY, 2002; MOTT; CERQUEIRA, 2003; JESUS, 2014)

Em razão do compartilhamento da vivência da transgeneridade entre todas as pessoas trans de qualquer gênero, agrupo no conceito de transfobia todas as formas de violência contra pessoas trans, aí incluídas mulheres transexuais, travestis, pessoas andróginas, pessoas não binárias, homens trans, etc. A partir dos conceitos que desenvolvi no trabalho, apresento o seguinte fluxograma para apresentar a relação entre a transgeneridade e a transfobia. O fluxograma não indica causalidade nem uma sucessão, nem relação necessária, mas um desdobramento do conceito como um fenômeno ou 
fato: Transgeneridade $>$ Estigmatização $>$ Abjeção $>$ Transfobia.

Não coincidentemente, aos privilégios conferidos às pessoas que se comportam conforme o regime cis correspondem aos tipos de violências que atingem pessoas trans (LANZ, 2015, p.73-74) ${ }^{10}$ : generalização - imposição forçada do gênero -, leitura equivocada do gênero, reenvio forçado aos símbolos da cisgeneridade, ${ }^{11}$ exclusão social nas instâncias privilegiadas de sociabilidade e socialização - família, escola, centro espiritual, trabalho, rua, órgãos públicos etc. -, recusa do reconhecimento da identidade trans reivindicada, com as consequências legais negativas, interdição ao uso normal de ambientes - rua, banheiros, órgãos públicos, praia, cinema, clube, delegacias, hospitais, etc. -, patologização, medicalização, genitalização da identidade, perturbação psicológica, assédio, violência discursiva no uso do nome, eliminação física através da morte, redução da expectativa e qualidade de vida, etc. A cisgeneridade também pode ser entendida como um modo de conhecer o mundo, porque permite e incentiva a ignorância cis de todas as violências que as pessoas trans sofrem para que se sustente assim um regime de corporalidade forçado.

Para o conceito de transfobia não importa a orientação sexual; não se trata da manifestação do desejo erótico ou do afeto que violem a heterossexualidade compulsória. ${ }^{12}$ Da mesma forma, para sofrer a violência transfóbica, adianto que não é necessário que alguém se identifique como pessoa trans. Sabemos que o agressor não pergunta se a pessoa trans reivindica alguma identidade de mulher transexual, travesti, pessoa não binária, queer ou homem trans - ou não é pessoa trans , ele apenas a ataca.

Agora quero argumentar mais sobre a necessidade de haver identidade trans para a vitimização por transfobia, usando o fluxograma que apresentei. Em sua teoria, Erving Goffman (1988, p.12) explica que pessoas "normais" analisam pessoas estigmatizadas ou "estranhos", no contato face a face, coletando uma série de informações, "primeiros aspectos", para formar a imagem da identidade social da pessoa. Alguém que lê uma pessoa quando pela primeira vez a conhece em carne e osso analisa o seu corpo e analisa sua expressão de gênero, e faz alguma imaginação sobre ela, usando os estereótipos disponíveis, que são os parâmetros de masculinidade

\footnotetext{
${ }^{10}$ São 35 privilégios da cisgeneridade os listados por Letícia Lanz em seu livro.

${ }^{11}$ Nas biografias de João W. Nery e Roberta Close, tanto ele quanto ela narram episódios de reenvio forçado à cisgeneridade, em suas vidas em que sentiram necessidade de construir o volume do pênis com meias (NERY, 2011, p.201) e de marcar uma menstruação com miúdos de galinha. (RITO, 1998, p.24)

12 Isso não elimina ou perturba as imbricações que a transfobia tem com outros tipos de violências derivadas das normas de gênero, como a lesbofobia, a bifobia, a homofobia ou a misoginia.
} 
e feminilidade. O conjunto das supostas qualidades e atributos de alguém é chamada identidade social virtual; quando esse alguém "prova possuir", nas palavras de Goffman, todas essas qualidades e atributos, ela tem uma identidade social real.

Amara Moira Rodovalho (2017) aponta uma problematização para a ideia de autoidentificação: ela "segue sendo importante para desdemonizarmos a escolha por cruzar a linha, a escolha por ceder a essa pulsão e nos deixar levar para além do que fomos criadas para ser" (RODOVALHO, 2017, p.368), ou seja, para desnaturalizar o gênero e para visibilizar a transgeneridade. A autora afirma que "na maioria das interações sociais não haverá tempo hábil para você dizer o que é, seu corpo tendo que se fazer capaz de transmitir a mensagem da forma mais inequívoca possível” (RODOVALHO, 2017, p.368), e é aí que surge a busca da pessoa trans em parecer cis (passabilidade) e diminuir todos os constrangimentos, preconceitos e violências que ela sofreria caso se apresentasse simplesmente como é, trans.

O problema é que apresentar-se e autoidentificar-se como qualquer coisa não é um ato unilateral (RODOVALHO, 2017, p.368). No processo de leitura há um emissor e os destinatários da mensagem. O processo de ler o gênero de alguém envolve o acesso menor ou maior aos repertórios culturais do que seja o gênero, do que sejam a masculinidade ou a feminilidade e de quais fronteiras podem existir entre uma e outra.

“O 'parecer mulher' é fundamento do 'ser mulher': a trans que seja lida como cis estará ao abrigo da transfobia nas situações em que esta leitura não for posta em dúvida, ao passo que a cis lida como trans sofrerá transfobia ainda que não se entenda, não se identifique como trans", diz Rodovalho. (2017, p.369, grifo meu) Estou concordando com Amara Moira e quero tomar a essa afirmação da autora e suas consequências para pensar a violência contra pessoas trans e o conceito de transfobia.

O homem cis afeminado e a mulher cis masculinizada, qualquer que seja sua orientação sexual, podem sofrer transfobia, porque representam mal a cisgeneridade. A transformista, a drag queen, o drag king e outras artistas que fazem montação rompem ocasionalmente o gênero e perturbam a leitura linear do corpo e podem estar sujeitas à transfobia. Para mim, parece não ser necessário reivindicar-se pessoa trans ou, para usar Goffman, ter uma identidade social real trans, para sofrer transfobia. Talvez seja bastante apenas a aparência trans, ou seja, uma identidade social virtual trans, como veremos no caso abaixo. Para sofrer a sanção no sistema de gênero/sexualidade, ao transgressor basta apenas transgredir a regra, qualquer que seja sua identidade. 
Transpor o limite da cisgeneridade é também transpor o limite do gênero. A transfobia então pune as pessoas cis que violam a norma da cisgeneridade. Reconheço que essa é uma defesa arriscada de um conceito amplo de transfobia.

A partir da notícia de Neto Lucon (2016), conhecemos o caso de Luiz Carlos Ruas, homem cis, vendedor ambulante, que, ao defender uma travesti e um gay de um ataque de dois homens cis, no dia 25/12/2016, no Metrô de São Paulo, capital, foi assassinado covardemente em razão de tê-las defendido. Em relação à travesti, por defendê-la, Ruas morreu pela transfobia. ${ }^{13}$ No caso de Luiz Carlos Ruas, que morreu ao defender uma pessoa trans, vejo que a violência é reservada a todas as pessoas cis que recusam reiterar o poder da cisgeneridade. A depreciação do estigma foi quebrada pela empatia ${ }^{14}$ e voltou-se contra quem defendeu a travesti, e o contaminou, permitindo que uma pessoa cis fosse punida com transfobia, com a morte. Eu também posso apontar outros casos de violência, como já mencionei, não muito explícitos: como exemplo, as pessoas trans que permanecem armarizadas, fingindo uma cisgeneridade que não querem ter, graças à coação de discursos e símbolos transfóbicos que circulam livremente entre nós.

Portanto, em síntese, há pelo menos dois casos de transfobia que pode atingir pessoas não trans: (1) má representação da cisgeneridade e (2) a recusa do poder e da violência decorrentes da cisgeneridade.

\footnotetext{
${ }^{13}$ Segundo Nassif (2017), também recordamos o caso de agressão contra um pai e um filho, que trocavam abraços em público em uma exposição em São João da Boa Vista/SP, em 15/07/2011. O caso por sua vez era de homofobia, e os agredidos eram dois homens heterossexuais.

${ }^{14}$ Compreensão benévola da diferença e da multiplicidade humana, rompendo o ciclo de abjeção.
}

Periódicus, Salvador, n.11, v. 1, mai-out.2019 - Revista de estudos indisciplinares em gêneros e sexualidades 


\section{Referências}

BENTO, B. Brasil: país do transfeminícidio. Centro latino- americado em sexualidade e direitos humanos, Rio de Janeiro, 2014. Disponível em: http://www.clam.org.br/destaque/conteudo.asp?cod=11606. Acesso em: 01 jun. 2017.

BETTCHER, T. M. Evil deceivers and make-believers: on transphobic violence ans the politics of illusion. In: AIZURA, A. Z.; STRYKER, S. (org.). The Transgender Studies Reader. New York: Routledge, 2013. p. 278- 290. v. 2.

BORNSTEIN, K. Gender terror, gender rage. In: WHITTLE, S.; STRYKER, S. (org.) The Transgender Studies Reader. Nova York: Routledge, 2006. p. 236-243. v. 1.

BORRILLO, D. Homofobia: história e crítica de um preconceito. Belo Horizonte: Autêntica Editora, 2015.

BRAH, A. Diferença, diversidade e diferenciação. Pagu, Campinas, n. 26, p. 329-376, 2006.

BUSIN, V. M. Morra para se libertar: estigmatização e violência contra travestis. 2015. Tese (Doutorado em Psicologia) - Instituto de Psicologia, Universidade de São Paulo, São Paulo, 2015.

BUTLER, J. Vida precária. Contemporânea, São Carlos, v. 1, n. 1, p. 13-33, 2011.

CARVALHO, M. F. L. Que mulher é essa? Identidade, política e saúde no movimento de travestis e transexuais. 2011. Dissertação (Mestrado em Saúde Coletiva) Programa de Pós Graduação em Saúde Coletiva, Universidade do Estado do Rio de Janeiro, Rio de Janeiro, 2011.

CRETTIEZ, X. Las formas de la violencia. Buenos Aires: Waldhuter, 2009.

EFREM FILHO, R. Corpos brutalizados: conflitos e materializações nas mortes de LGBT. Pagu, Campinas, n. 46, p. 311-340, 2016.

FIGARI, C. Las emociones de lo abyecto: repugnancia e indignación. In: SCRIABANO, A.; FIGARI, C. (comp.). Cuerpos(s), subjetividad(es) y conflicto(s): hacia una sociología de los cuerpos y las emociones desde Latinoamérica. Buenos Aires: CICCUS, 2009. p. 131-139.

GOFFMAN, E. Estigma: notas sobre a manipulação da identidade deteriorada. 4. ed. Rio de Janeiro: LTC, 1988.

HEYES, C. Feminist solidarity after queer theory: the case of transgender. In: AIZURA, A. Z.; STRYKER, S. (org.). The Transgender Studies Reader. Nova York: Routledge, 2013. p. 201212. v. 2.

JESUS, J. G. Transfobia e crimes de ódio: assassinatos de pessoas transgênero como genocídio. (In)visibilidade Trans 2. História Agora, [s. l], v. 16, n. 2, p. 101-123, 2013.

LAMBLE, S. Retelling racialized violence, remaking white innocence: the politics of interlocking oppressions in transgender day of remembrance. In: AIZURA, A. Z.; STRYKER, S. (org.). The Transgender Studies Reader. Nova York: Routledge, 2013. p. 30-45. v. 2.

LANZ, L. O corpo da roupa: a pessoa transgênera entre a conformidade e a transgressão das normas de gênero, uma introdução aos estudos transgêneros. Curitiba: Transgente, 2015.

LEITE JUNIOR, J. Nossos corpos também mudam: sexo, gênero e a invenção das categorias "travesti" e "transexual" no discurso científico. 2008. Tese (Doutorado em Ciências Sociais)Programa de Pós Graduação em Ciências Sociais, Pontifícia Universidade Católica de São Paulo, São Paulo, 2008.

LUCON, N. Expectativa de vida de travestis é de 35 anos, mas deve aumentar, afirma psicólogo social. NLUCON, [ $S . \quad l \quad], 18$ fev. 2015. Disponível em: https://nlucon.com/2015/02/18/expectativa-de-vida-de-travestis-e-de-35-anos-mas-deveaumentar-afirma-psicologo-social/. Acesso em: 07 jun. 2017- 13 jul. 2018.

LUCON, N. Vendedor ambulante tenta salvar travesti e gay de ataque e é assassinado em metrô de SP. NLUCON, [ s. l], 26 dez. 2016. Disponível em: 
https://nlucon.com/2016/12/26/vendedor-ambulante-tenta-salvar-travesti-e-gay-deataque-e-e-assassinado-em-metro-de-sp/. Acesso em: 01 jun. 2017.

MOTT, L.; CERQUEIRA, M. Matei porque odeio gay. Salvador: Editora Grupo Gay da Bahia, 2003.

NASSIF, L. Homofobia: a agressão a pai e filho. GGn, São Paulo, 19 jul. 2017. Disponível em: https://jornalggn.com.br/noticia/homofobia-a-agressao-a-pai-e-filho/ .Acesso em: 01 jun. 2017.

NERY, J. W. Viagem solitária: memórias de um transexual 30 anos depois. São Paulo: Leya, 2011.

PRINS, B.; MEIJER, I. C. Como os corpos se tornam matéria: entrevista com Judith Butler. Estudos Feministas, Florianópolis, v. 10, n. 1, p. 155-167, 2002

RITO, L. Muito prazer, Roberta Close. Rio de Janeiro: Rosa dos Tempos, 1998.

RODOVALHO, A. M. O cis pelo trans. Estudos Feministas, Florianópolis, v. 25, n. 1, p. 365373, 2017.

SAFFIOTI, H. I. B. Contribuições feministas para o estudo da violência de gênero. Pagu, Campinas, n. 16, p. 115-136, 2001.

SMIGAY, K. E. V. Sexismo, homofobia e outras expressões correlatas de violência: desafios para a psicologia política. Psicologia em Revista, Belo Horizonte, v. 8, n. 11, p. 32-46, 2002. 